\title{
Kontrol dan Monitoring Stop Kontak Berbasis Android
}

\author{
Indra Dwisaputra ${ }^{1}$, Yudhi $^{2}, K^{\prime}$ K Anggrainy ${ }^{3}$, Steven Novaldy ${ }^{4}$ \\ 1,2,3,4) Jurusan Teknik Elektro dan Informatika Politeknik Manufaktur Negeri Bangka Belitung \\ Jl. Timah Raya Kawasan Industri Air Kantung Sungailiat, 071793286 \\ email:: ${ }^{1)}$ wisaputra.indra@gmail.com, ${ }^{2)}$ yudhijais@gmail.com, ${ }^{3)}$ kkanggrainy@gmail.com, ${ }^{4}$ snovaldy54@ gmail.com,
}

\begin{abstract}
ABSTRAK
Pertumbuhan konsumsi listrik semakin banyak dikarenakan pertumbuhan penduduk dan ekonomi dunia. Monitoring dan kontrol konsumsi energi listrik diharapkan dapat membantu efisiensi. Salah satu perangkat yang digunakan menghubungkan sumber listrik ke perangkat listrik adalah elektrik soket. Penelitian ini dilakukan dengan cara eksperimen dan memodifikasi stop kontak yang umum di pasaran. Stop kontak ditambahkan sensor tipe PZEM-004T yang dapat membaca tegangan, arus dan daya. Data yang diambil dari sensor kemudian dibandingkan dengan alat power quality analyzer untuk mengetahui tingkat kepresisian pengukuran. Real time clock tipe DS3231 digunakan untuk menghitung pemakaian beban secara real time. Data diolah oleh mikrokontroller kemudian mengirimkannya ke smartphone. Pengguna dapat memonitor biaya pemakaian dalam rupiah (Rp). Komunikasi stop kontak ke smartphone menggunakan bluetooth tipe HC-05 dengan jarak maksimal 10 m. Relay dipasang untuk memutuskan aliran listrik sesuai dengan timer yang telah diatur. Berdasarkan hasil pengujian alat data yang dimonitoring memiliki perbedaan dengan persentase 0,13\% untuk tegangan, 2,26\% untuk arus dan 1,75\% untuk daya.
\end{abstract}

Kata kunci: Android, Arduino, Bluetooth, Sensor daya, Stopkontak

\begin{abstract}
The growth in electricity consumption is increasing due to population growth and the world economy. Monitoring and controlling the consumption of electrical energy is expected to help efficiency. One of the devices used to connect a power source to an electrical device is an electric socket. This research was conducted by experimenting and modifying common sockets on the market. The socket is added with a sensor type PZEM-004T which can read voltage, current and power. The data taken from the sensor is then compared with a power quality analyzer to determine the level of measurement precision. Real time clock type DS3231 is used to calculate load usage in real time. The data is processed by the microcontroller and then sends it to the smartphone. Users can monitor usage fees in rupiah (Rp). Communication socket to smartphone using bluetooth type HC-05 with a maximum distance of $10 \mathrm{~m}$. Relay is installed to cut off electricity according to the timer that has been set. Based on the test results, the monitored data tool has a difference with a percentage of $0.13 \%$ for voltage, $2.26 \%$ for current and $1.75 \%$ for power.
\end{abstract}

Keywords: Android, Arduino, Bluetooth, Power sensor, wall socket

\section{PENDAHULUAN}

Energi listrik merupakan energi yang sangat vital dalam operasional perusahaan maupun rumah tangga. Hampir semua peralatan dan sumber penerangan yang digunakan berasal dari energi listrik. Namun dalam pemakaiannya banyak dikeluhkan adanya kerugian pada penggunaan energi listrik ini. Hal ini terbukti dari cepat habisnya pulsa listrik Kwh Prabayar. Terlebih apabila ini terjadi dilingkungan kantor atau perusahaan maka akan mengakibatkan anggaran biaya yang cukup besar. Untuk mengefisiensikan pemakaian listrik, maka perlu dilakukan manajemen pemakaian listrik untuk penghematan energi.

Sebelumnya telah dibuat alat ukur daya listrik berupa power meter digital berbasis mikrokontroler AVR ATmega8535 menggunakan perangkat keras berupa sensor arus ACS712. Alat ini dapat mengukur dan menampilkan tegangan, arus dan daya listrik suatu peralatan elektronik rumah tangga yang hanya ditampilkan melalui LCD [1]. Pembacaan nilai sensor arus, sensor tegangan dan daya dengan beban pada beban penerangan dan stopkontak dan motor dengan menggunakan sensor ACS712 memiliki akurasi monitoring terhadap arus memiliki rata-rata error yang relatif kecil dimana pada beban penerangan 3.96\% dan pada beban stopkontak adalah $1.13 \%$ [2]. Sensor ACS712 masih belum stabil dalam mendeteksi arus [3]. Monitoring dan kontrol lampu menggunakan sensor PZEM menghasilkan error tegangan $0,05 \%$, selisih arus $17,2 \mathrm{~mA}$ dan error daya $1,06 \%$ [4]. Sistem monitoring stop kontak dengan menggunakan metode pervasive computing dapat melakukan discovery dengan rata-rata waktu total 
RESISTOR (Elektronika Kendali Telekomunikasi Tenaga Listrik Komputer) Vol. 4 No. 1 e-ISSN : 2621-9700, p-ISSN : 2654-2684

sebesar 1156,3 ms [5]. Sistem pengiriman data dapat menggunakan modul NRF24L01 dan mengirimkan data secara wireless hingga jarak 30 meter [6]. Metode monitoring beban intrusif dapat digunakan pada stop kontak pintar untuk mengurangi komponen sensor paremeter listrik dengan cara membandingkan karakteristik dengan database yang ada [7]. Algoritma manajemen energi menunjukkan pengurangan penggunaan energi sebesar 0,811 $\mathrm{kWmin}(0,0134 \mathrm{kWh})$ setelah penggunaan soket pintar sebagai pengontrol beban selama 24 menit [8].

Paper ini membahas bagaimana sistem monitoring yang dapat mengecek penggunaan daya yang digunakan oleh setiap beban listik yang digunakan. Dengan ini penulis memodifikasi stopkontak yang sudah ada menjadi stopkontak yang bisa memonitoring penggunaan daya listrik dan biaya penggunaan listrik yang dikontrol melalui aplikasi yang berbasis android secara langsung. Alat ini mampu mengecek lebih detail setiap daya yang digunakan pada beban listrik dan biaya dari beban listrik tersebut melalui android. Sehingga pengguna dapat mengetahui penggunaan daya pada setiap beban dengan mudah melalui Android. Tujuan/maksud dari penelitian ini adalah pengguna dapat mengontrol penggunaan dua buah Stopkontak melalui Android dan dapat mengecek penggunaan beban listrik yang telah digunakan melalui Android.

\section{Energi Listrik dan Daya}

Energi merupakan kemampuan untuk melakukan kerja, energi merupakan kerja tersimpan.

Daya listrik dibagi menjadi tiga, yaitu daya aktif, daya reaktif dan daya semu. Daya dengan satuan Joule/detik atau watt disebut sebagai daya aktif. Simbolnya adalah P. Daya aktif adalah daya sebenarnya yang dihamburkan atau dipakai oleh beban. Daya aktif dihitung dengan persamaan:

$\mathrm{P}=\mathrm{V} \cdot \mathrm{I} \cdot \cos \Phi$

$$
\begin{aligned}
\text { Keterangan : } & \mathrm{V}=\text { tegangan, volt } \\
& \mathrm{I}=\text { arus, ampere } \\
& \Phi=\text { sudut phi, derajat }
\end{aligned}
$$

Daya reaktif satuannya adalah VAR (Voltampere - reactive). Daya reaktif (Q) ini merupakan jumlah daya yang diperlukan untuk pembentukan medan magnet, daya reaktif juga dipahami sebagai daya yang tidak dihamburkan olehan atau dengan kata lain merupakan daya yang diserap namun dikembalikan ke sumbernya. Daya reaktif dapat dihitung dengan persamaan :

$\mathrm{P}=\mathrm{V} \cdot \mathrm{I} \cdot \sin \Phi$

$$
\begin{gathered}
\text { Keterangan }=\mathrm{V}=\text { tegangan, volt } \\
\mathrm{I}=\text { arus, } \text { ampere } \\
\Phi=\text { sudut phi, derajat }
\end{gathered}
$$

Daya tampak merupakan hasil penujumlahan trigonometri daya aktif dan reaktif yang disimbolkan dengan S. Dengan satuannya adalah VA (Voltampere). Daya tampak dapat dihitung menggunakan persamaan :

$\mathrm{S}=\mathrm{V} \cdot \mathrm{I}$

Keterangan $=\mathrm{V}=$ tegangan, volt

$$
\mathrm{I}=\text { arus, ampere }
$$

Daya adalah ukuran kecepatan kerja dilakukan atau kecepatan energi dikeluarkan, sehingga energi yang digunakan oleh alat listrik adalah laju penggunaan daya dikalikan dengan waktu selama alat tersebut digunakan. Bila diukur satu jam pemakaian, maka dapat dihitung dengan menggunakan persamaan :

Daya $($ per-jam $)=\frac{\text { V.I }}{1000}$

Setelah melakukan wawancara dengan salah satu karyawan Perusahaan Listrik Negara, penulis mendapatkan info mengenai biaya pemakaian listrik per-KWh yaitu 1450 per-Kwh dengan konsumsi daya non-subsidi dari 900 VA sampai 3300 VA. Adapun biaya perhitungan listrik pada setiap beban yang digunakan dalam satuan detik sebagai berikut :

Biaya $($ per-jam $)=$ daya $($ per-jam $) \cdot 1450$

$$
\begin{gathered}
\text { Biaya (per-detik) } \quad=\frac{V . I}{3600} \times 1,45 \\
\text { Keterangan }=\quad \mathrm{V}=\text { tegangan, volt } \\
\mathrm{I}=\text { arus, ampere }
\end{gathered}
$$

\section{Android}

Sulihati dan Andriyani pada jurnal Sains dan Teknologi April 2016, Universitas Tama Jagakarsa, Jakarta Selatan yang berjudul Aplikasi Akademik Online Berbasis Mobile Android mengatakan bahwa Android adalah aplikasi sistem operasi untuk telepon seluler yang berbasis Linux. Android menyediakan platform terbuka bagi para pengembang untuk menciptakan aplikasi mereka sendiri untuk digunakan oleh bermacam piranti bergerak [9].

Android memang dirancang untuk dipasang pada perangkat-perangkat mobile touchscreen (smartphone dan tablet). Sehingga sistem operasi yang berada di dalam smartphone saat ini memang menyesuaikan dari spesifikasi kelas low-end hingga high-end. Sehingga perkembangan sistem Android memang cukup meningkat tajam. Android 
RESISTOR (Elektronika Kendali Telekomunikasi Tenaga Listrik Komputer) Vol. 4 No. 1 e-ISSN : 2621-9700, p-ISSN : 2654-2684

merupakan sistem operasi yang terbuka (open source) yang mana berarti jika pihak Google memperbolehkan dan membebaskan bagi pihak manapun untuk dapat mengembangkan sistem operasi tersebut.

\section{METODOLOGI}

Desain Peralatan dilakukan untuk menghasilkan alat yang sesuai dengan spesifikasi yang diinginkan dalam pembuatan alat ini, maka dibutuhkan penganalisaan dan perencanaan peralatan yang akan dibuat tersebut meliputi:

1. Perencanaan software yang akan digunakan

2. Perencanaan biaya pembuatan alat

3. Perencanaan konstruksi peralatan

Setelah desain peralatan selesai maka tahap awal pembuatan hardware yaitu:

1. Pembuatan kontruksi box stopkontak

2. Pemasangan komponen-komponen yang digunakan

Perancangan hardware Stopkontak adalah proses pembuatan desain Stopkontak. Pembuatan desain ini mencakup kontruksi Stopkontak yang akan dibuat. Proses pembuatan desain dibuat secara bertahap dan dimulai dari perancangan masingmasing part atau bagian dari Stopkontak. Ukuran atau dimensi dari Stopkontak yang akan dibuat yaitu 18,5 $\mathrm{cm} \times 11,5 \mathrm{~cm} \times 6 \mathrm{~cm}$

Perencanaan program pada Arduino UNO R3 merupakan langkah awal dalam mendesain atau merancang bagaimana system pengontrolan yang akan dibuat. Pembuatan program Arduino UNO R3 ini dibuat untuk melihat alur pemograman pada Stopkontak. Pembuatan program yang dilakukan meliputi inisial variabel, pembacaan nilai pada sensor-sensor yang digunakan, pembuatan pemograman mengontrol Stopkontak, pembuatan pemograman pengiriman dan penerimaan data lewat Bluetooth, pembuatan logika pemograman, pembuatan pembuatan menghitung data yang didapatkan, pembuatan pemograman penyimpanan data, pembuatan pemograman waktu, dan pembuatan pemograman secara keseluruhan. Sedangkan untuk pemrograman software android dilakukan secara online melalui website App Inventor 2.

\section{HASIL DAN PEMBAHASAN Blok Diagram sistem}

Berikut merupakan sistem diagram elektrikal dari penelitian ini.

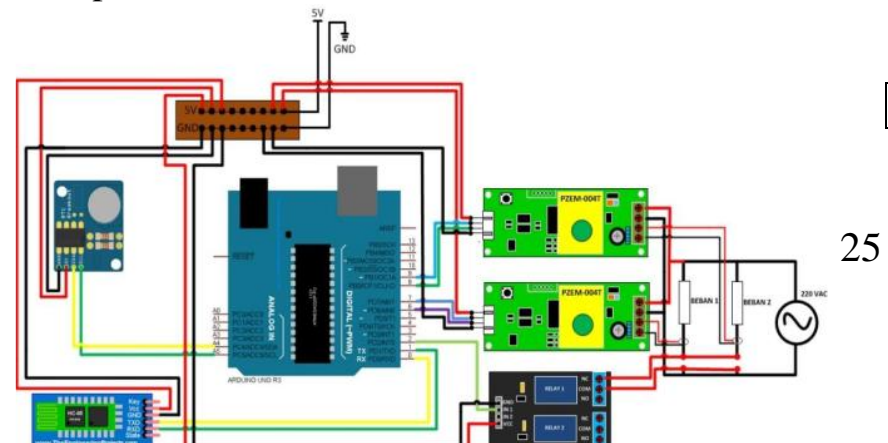

\section{Gambar 1. Sistem diagram elektrikal}

Pada gambar ini input terdiri dari modul sensor PZEM-004T sebagai mendeteksi tegangan, arus, dan daya, input selanjutnya yaitu real time clock DS3231 sebagai pemberi hari dan jam. Pada proses terdiri dari Arduino UNO R3 sebagai tempat pengolahan semua data yang didapat dari input, sedangkan untuk Bluetooth HC-05 sebagai komunikasi untuk mengirim data yang diproses dari Arduino untuk dikirimkan ke Android melalui komunikasi Bluetooth. Pada output terdapat relay sebagai pengontrolan untuk ON atau OFF, sedangkan pada Android sebagai aplikasi untuk mengontrol dan mengecek daya dan biaya dari setiap beban yang digunakan.

\section{Pengujian Tegangan PZEM-004T}

PZEM-004T ini digunakan sebagai sensor yang berguna untuk mengecek tegangan, arus, dan daya yang didapat dari setiap beban yang digunakan. Modul ini sudah dilengkapi sensor tegangan dan sensor arus (CT) yang sudah terintegrasi. Dalam alat ini khusus untuk penggunaan dalam ruangan (indoor) dan beban yang terpasang tidak diperbolehkan melebihi daya yang sudah ditetapkan. Gambar pengujian tegangan adalah sebagai berikut.

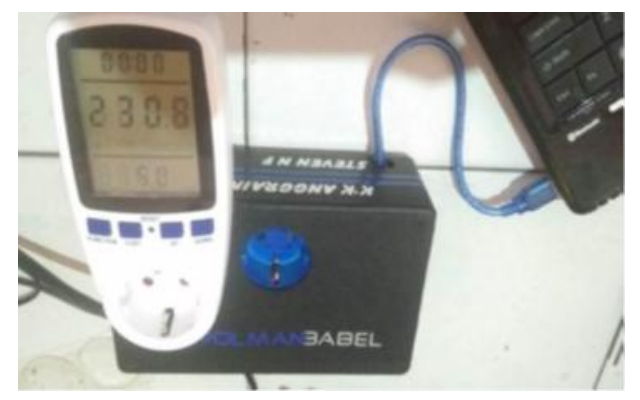

Gambar 2. Pengujian tegangan

Berikut adalah tabel pengujian tegangan pada modul sensor PZEM-004T.

Tabel 1. Pengujian tegangan 
RESISTOR (Elektronika Kendali Telekomunikasi Tenaga Listrik Komputer) Vol. 4 No. 1 e-ISSN : 2621-9700, p-ISSN : 2654-2684

\begin{tabular}{|c|c|c|c|}
\hline & $\begin{array}{c}\text { Tegangan } \\
(\mathrm{V})\end{array}$ & $\begin{array}{c}\text { Tegangan } \\
(\mathrm{V})\end{array}$ & \\
\hline Solder & $230,0-$ & $229,7-$ & $0,13 \%$ \\
& 231,1 & 230,8 & \\
\hline $\begin{array}{c}\text { Rice cooker } \\
\text { (mode cook) }\end{array}$ & $230,0-$ & $229,7-$ & $0,13 \%$ \\
\hline $\begin{array}{c}\text { Rice cooker } \\
\text { (mode warm) }\end{array}$ & $230,0-$ & 230,8 & \\
\hline Lampu & 231,1 & $230,7-8$ & $0,13 \%$ \\
$45 w a t t$ & 231,1 & $229,7-$ & $0,13 \%$ \\
\hline \multicolumn{3}{|c|}{ Rata-rata } & $0.13 \%$ \\
\hline
\end{tabular}

\begin{tabular}{|c|c|c|c|c|}
\hline \multirow{3}{*}{ No } & \multirow{3}{*}{ Beban } & Arduino & Pengukuran & Error \\
\hline & & Arus & Arus & \\
\hline & & (A) & (A) & \\
\hline \multirow{3}{*}{1} & \multirow{3}{*}{ Solder } & 0,26 & 0,267 & $2,62 \%$ \\
\hline & & 0,25 & 0,259 & $3,47 \%$ \\
\hline & & 0,27 & 0,271 & $0,37 \%$ \\
\hline \multirow{3}{*}{2} & \multirow{3}{*}{$\begin{array}{c}\text { Rice } \\
\text { cooker } \\
\text { (mode } \\
\text { cook) }\end{array}$} & 2,09 & 2,123 & $1,55 \%$ \\
\hline & & 2,11 & 2,152 & $1,95 \%$ \\
\hline & & 2,09 & 2,136 & $2,15 \%$ \\
\hline \multirow{3}{*}{3} & \multirow{3}{*}{$\begin{array}{c}\text { Rice } \\
\text { cooker } \\
\text { (mode } \\
\text { warm) }\end{array}$} & 0,21 & 0,217 & $3,22 \%$ \\
\hline & & 0,21 & 0,215 & $2,32 \%$ \\
\hline & & 0,22 & 0,225 & $2,22 \%$ \\
\hline \multirow{3}{*}{4} & \multirow{3}{*}{$\begin{array}{l}\text { Lampu } \\
45 \text { watt }\end{array}$} & 0,31 & 0,32 & $3,12 \%$ \\
\hline & & 0,33 & 0,336 & $1,78 \%$ \\
\hline & & 0,32 & 0,328 & $2,43 \%$ \\
\hline 5 & \multicolumn{3}{|c|}{ Rata-rata } & $2,27 \%$ \\
\hline
\end{tabular}

Dari hasil pengujian tegangan dengan modul sensor PZEM-004T ini menggunakan beban solder, rice cooker dengan mode cook, rice cooker dengan mode warm dan lampu 45 watt, dari hasil pengujian tersebut didapatkan eror dengan nilai sebesar $0.13 \%$ sama dengan hasil rata-ratanya. Dari hasil pengujian dan analisa dapat disimpulkan bahwa modul sensor PZEM-004T yang digunakan untuk pengecekan tegangan sesuai dengan perancangan yang diinginkan.

\section{Pengujian Arus}

Tabel pengujian arus pada modul sensor PZEM-004T dapat dilihat pada tabel 2. Gambar pengujian arus menggunakan alat ukur ditampilkan pada gambar 3 .

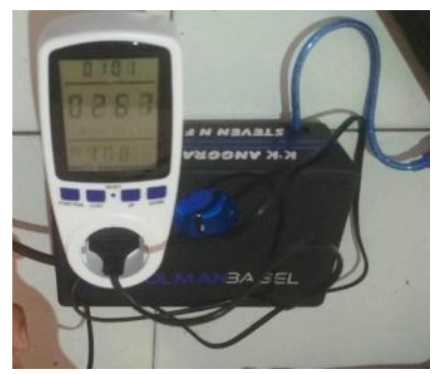

Gambar 3. Pengujian arus.

Dari hasil pengujian arus dengan modul sensor PZEM-004T ini menggunakan beban solder, rice cooker dengan mode cook, rice cooker dengan mode warm dan lampu 45 watt, dari hasil pengujian tersebut didapatkan eror terbesar dengan nilai sebesar 3,47\% dan dengan hasil rata-ratanya yaitu 2,267 \%. Dari hasil pengujian dan analisa dapat disimpulkan bahwa modul sensor PZEM-004T yang digunakan untuk pengecekan arus sesuai dengan perancangan yang diinginkan.

Tabel 2. Hasil pengujian arus

Pengujian Daya

Berikut adalah tabel pengujian daya pada modul sensor PZEM-004T.

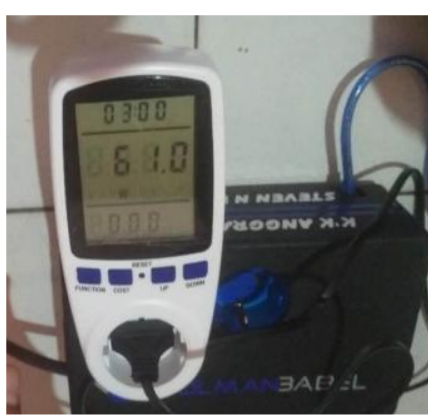

Gambar 4. Pengujian daya

Dari hasil pengujian daya dengan modul sensor PZEM-004T ini menggunakan beban solder, rice cooker dengan mode cook, rice cooker dengan mode warm dan lampu 45 watt, dari hasil pengujian tersebut didapatkan eror terbesar dengan nilai sebesar 3,02\% dan dengan hasil rata-ratanya yaitu $1,755 \%$. Dari hasil pengujian dan analisa dapat disimpulkan bahwa modul sensor PZEM-004T yang digunakan untuk pengecekan daya sesuai dengan perancangan yang diinginkan.

Tabel 3. Hasil pengujian daya

\begin{tabular}{|c|c|c|c|c|}
\hline No & Beban & Arduino & Pengukuran & \multirow{2}{*}{ Error } \\
\cline { 3 - 4 } & & Daya & Daya & \\
\hline
\end{tabular}


RESISTOR (Elektronika Kendali Telekomunikasi Tenaga Listrik Komputer) Vol. 4 No. 1 e-ISSN : 2621-9700, p-ISSN : 2654-2684

\begin{tabular}{|c|c|c|c|c|}
\hline & & (VA) & (VA) & \\
\hline \multirow[t]{3}{*}{1} & \multirow[t]{3}{*}{ Solder } & 59,94 & 61.47 & $2,48 \%$ \\
\hline & & 57,64 & 59.63 & $3,33 \%$ \\
\hline & & 62.24 & 62.39 & $0.24 \%$ \\
\hline \multirow[t]{3}{*}{2} & \multirow{3}{*}{$\begin{array}{c}\text { Rice } \\
\text { cooker } \\
\text { (mode } \\
\text { cook) }\end{array}$} & 481.85 & 488.82 & $1,42 \%$ \\
\hline & & 486.46 & 494.5 & $1,82 \%$ \\
\hline & & 481.85 & 489.9 & $1,64 \%$ \\
\hline \multirow[t]{3}{*}{3} & \multirow{3}{*}{$\begin{array}{c}\text { Rice } \\
\text { cooker } \\
\text { (mode } \\
\text { warm) }\end{array}$} & 48.41 & 49.91 & $3.00 \%$ \\
\hline & & 48.41 & 49.45 & $3.02 \%$ \\
\hline & & 50.72 & 51.75 & $1,99 \%$ \\
\hline \multirow[t]{4}{*}{4} & \multirow{3}{*}{$\begin{array}{l}\text { Lampu } \\
\text { 45watt }\end{array}$} & 45.91 & 46.42 & $1.1 \%$ \\
\hline & & 48.20 & 47.84 & $0.75 \%$ \\
\hline & & 48.20 & 48.07 & $0.27 \%$ \\
\hline & \multicolumn{3}{|c|}{ Rata-rata } & $1,76 \%$ \\
\hline
\end{tabular}

\section{Aplikasi Android ( Stopkontak )}

Pembuatan aplikasi Android dilakukan menggunakan software App Inventor secara online menggunakan PC/Komputer. Pada saat akan menggunakan, maka App Inventor 2 akan meminta data email user, dimana yang nantinya server app inventor akan menyimpan data yang berupa project user yang sudah dikerjakan. Ketika user akan mengakses project data yang dikerjakan sebelumnya secara otomatis sehingga user hanya perlu masuk ke home App Inventor 2, kemudian kembali pada project atau aplikasi yang telah dibuat. Berikut merupakan layout Screen 1 dan Screen 2 pada Android.

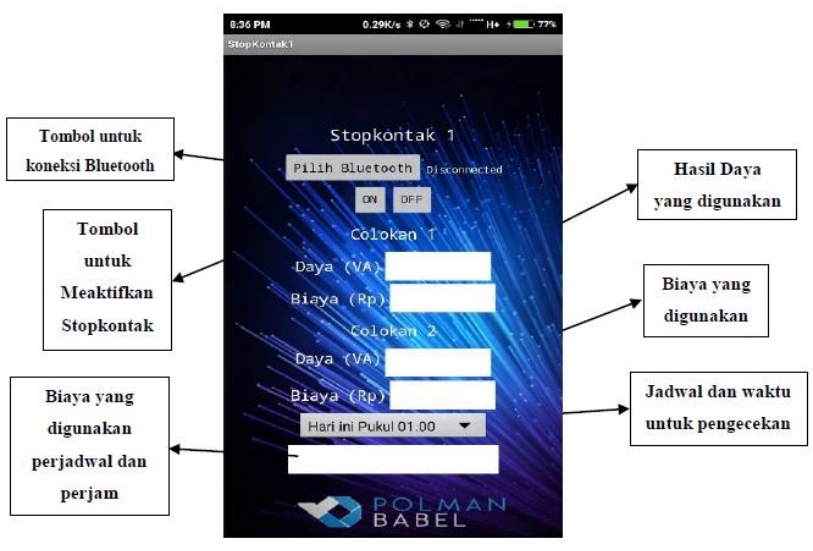

Gambar 5. Aplikasi Android
Setelah bagian hardware dan software dari Stopkontak telah dibuat, proses selanjutnya adalah pengujian terhadap system yang telah dibuat pada Stopkontak. Pengujian system ini dilakukan untuk menguji serta melihat bagaimana hasil yang akan didapatkan setelah melakukan perancangan, pembuatan, dan pengujian pada masing-masing hardware maupun software. Berikut ini adalah tabel pengujian keseluruhan alat dan aplikasi.

Tabel 4. Hasil pengujian stop kontak dengan beban berbeda.

\begin{tabular}{|l|l|l|l|l|}
\hline No & Beban & $\begin{array}{l}\text { Daya } \\
\text { (VA) }\end{array}$ & $\begin{array}{l}\text { Biaya } \\
\text { (Rp) }\end{array}$ & $\begin{array}{l}\text { Waktu } \\
\text { (WIB) }\end{array}$ \\
\hline 1 & $\begin{array}{l}\text { Lampu } \\
45 \text { Watt }\end{array}$ & 43.85 & 61.52 & $\begin{array}{l}01.00- \\
02.00\end{array}$ \\
\hline 2 & $\begin{array}{l}\text { Lampu } \\
45 \text { Watt }\end{array}$ & 43.61 & 61.35 & $\begin{array}{l}02.00- \\
03.00\end{array}$ \\
\hline 3 & $\begin{array}{l}\text { Lampu } \\
45 \text { Watt }\end{array}$ & 43.35 & 61.27 & $\begin{array}{l}03.00- \\
04.00\end{array}$ \\
\hline 4 & $\begin{array}{l}\text { Lampu } \\
45 \text { Watt }\end{array}$ & 44.12 & 62.14 & $\begin{array}{l}04.00- \\
05.00\end{array}$ \\
\hline 5 & $\begin{array}{l}\text { Lampu } \\
45 \text { Watt }\end{array}$ & 43.78 & 61.46 & $\begin{array}{l}05.00- \\
06.00\end{array}$ \\
\hline 6 & $\begin{array}{l}\text { Kipas Angin } \\
\text { (mode 3) 50 Watt }\end{array}$ & 48.64 & 69.88 & $\begin{array}{l}09.00- \\
10.00\end{array}$ \\
\hline 7 & $\begin{array}{l}\text { Kipas Angin } \\
\text { (mode 3) 50 Watt }\end{array}$ & 48.53 & 69.64 & $\begin{array}{l}10.00- \\
11.00\end{array}$ \\
\hline 8 & $\begin{array}{l}\text { Kipas Angin } \\
\text { (mode 3) 50 Watt }\end{array}$ & 47.89 & 68.75 & $\begin{array}{l}11.00- \\
12.00\end{array}$ \\
\hline 9 & $\begin{array}{l}\text { Kipas Angin } \\
\text { (mode 3) 50 Watt }\end{array}$ & 47.95 & 68.83 & $\begin{array}{l}12.00- \\
13.00\end{array}$ \\
\hline 10 & $\begin{array}{l}\text { Kipas Angin } \\
\text { (mode 3) 50 Watt }\end{array}$ & 48.70 & 69.92 & $\begin{array}{l}13.00- \\
14.00\end{array}$ \\
\hline
\end{tabular}

Dari hasil pengujian dengan beban lampu 45 watt tersebut, tercantum pada Stopkontak 1 yang digunakan dalam kondisi $O N$, pada saat pengujian pada colokan 1 tercantum daya sebesar 43.61 VA dan biaya sebesar 55,30 rupiah yang di cek pada kisaran pukul 02.00-03.00 WIB pada aplikasi Stopkontak. Pada pengecekan jadwal penyimpanan biaya yang digunakan yaitu pada pukul 01.00-02.00 WIB yaitu sebesar 61,52 rupiah. Maka dari itu pengontrolan dan pengecekan beban yang digunakan pada Stopkontak dan aplikasi Stopkontak berjalan dengan baik.

\section{Pengujian Bluetooth HC-05}

Adapun hasil pengujian yang dilakukan pada Bluetooth HC-05 untuk melihat terdeteksi atau tidaknya data yang dikirmkan aplikasi Stopkontak dapat dilihat pada tabel 5 .

\section{Pengujian Stopkontak}


RESISTOR (Elektronika Kendali Telekomunikasi Tenaga Listrik Komputer) Vol. 4 No. 1 e-ISSN : 2621-9700, p-ISSN : 2654-2684

Tabel 5 Hasil Pengujian Bluetooth HC-05

\begin{tabular}{|c|c|c|c|}
\hline \multirow{2}{*}{ No } & \multirow{2}{*}{ Jarak } & \multicolumn{2}{|c|}{ Status } \\
\cline { 3 - 4 } & & Tanpa Penghalang & Dengan Penghalang \\
\hline 1 & 1 Meter & Ya & Ya \\
\hline 2 & 2 Meter & Ya & Ya \\
\hline 3 & 3 Meter & Ya & Ya \\
\hline 4 & 4 Meter & Ya & Ya \\
\hline 5 & 5 Meter & Ya & Ya \\
\hline 6 & 6 Meter & Ya & Ya \\
\hline 7 & 7 Meter & Ya & Ya \\
\hline 8 & 8 Meter & Ya & Ya \\
\hline 9 & 9 Meter & Ya & Ya \\
\hline 10 & 10 Meter & Ya & \\
\hline
\end{tabular}

Dari pengujian yang dilakukan dapat dianalisa bahwa Bluetooth HC-05 yang digunakan dapat menerima data yang dikirim oleh aplikasi pada Android hingga jarak 10 meter dengan baik pada ruangan tanpa penghalang dan dengan penghalang, dan jika melebihi dari range tersebut maka kualitas konektivitas akan semakin kurang maksimal. Android dapat terhubung dan mengirim data dengan baik pada modul Bluetooth HC-05 yang digunakan pada Stopkontak. Dari hasil pengujian dan analisa dapat disimpulkan bahwa Bluetooth yang digunakan sesuai dengan perancangan yang diinginkan.

\section{SIMPULAN}

Dari hasil perancangan alat dan pengujian sistem kerja alat dapat ditarik kesimpulan sebagai berikut. Penggunaan dalam monitoring sensor PZEM-004T didapat bahwa mampu membaca nilai tegangan dengan rata-rata persentase error $0,13 \%$, arus $2,26 \%$ dan daya $1,75 \%$. Aplikasi dapat menerima data dari stop kontak memlalui jaringan bluetooth namun masih terbatas jarak $<10 \mathrm{~m}$. Alat dapat mengirimkan biaya pemakiaan dalam rupiah dengan mengkonversi dari pemakaian per $\mathrm{kWh}$. Dengan menggunakan Real Time Clock DS3231 didapat bahwa waktu yang ditampilkan sesuai dengan waktu sebenarnya. Penggunaan biaya peralatan listrik pada setiap jam terdapat dengan peralatan yang sama memiliki perbedaan perbedaan kecil $<$ Rp. 1 .

\section{DAFTAR PUSTAKA}

[1] T. Nusa, S. R. U. A. Sompie, and E. M. Rumbayan, "Sistem Monitoring Konsumsi Energi Listrik Secara Real Time Berbasis Mikrokontroler," E-J. Tek. Elektro Dan Komput., vol. 4, no. 5, pp. 19-26, 2015.

[2] M Fatkur Rozik and S. I. Haryudo, "MICROCONTROLLER ARDUINO PADA INSTALASI OTOMASI KELISTRIKAN INDUSTRI," J. Tek. Elektro, vol. 8, no. 1, pp. 219-227, 2019.
[3] D. A. Putra and R. Mukhaiyar, "Monitoring Daya Listrik Secara Real Time," J. Vocat. Tek. Elektron. Dan Inform., vol. 8, no. 2, 2020.

[4] I. Dwisaputra, Ocsirendi, H. Alqadri, and Y. Saputra, "MONITORING DAN KONTROL LAMPU SECARA WIRELESS DENGAN MENERAPKAN TREE TOPOLOGI," in Seminar Nasional Terapan Riset Inovatif, 2019, pp. 1074-1081.

[5] I. Zulfy, D. Syauqy, and S. R. Akbar, "Implementasi Pervasive Computing Pada Sistem Monitoring Konsumsi Daya Listrik Stop Kontak Rumah," J. Pengemb. Teknol. Inf. Dan Ilmu Komput. J-PTIIK Univ. Brawijaya, vol. 2, no. 9, pp. 2555-2561, 2018.

[6] I. Dwisaputra, B. Rolastin, and R. Afriansyah, "Monitoring water quality using star topology wireless sensor networks," J. Phys. Conf. Ser., vol. 1450 , no. 1 , 2020, doi: 10.1088/17426596/1450/1/012047.

[7] C. Yu, P. Chen, X. Liu, L. Zhao, M. Han, and Y. Yao, "Design of a Smart Socket Functioned with Electrical Appliance Identification," 2019 22nd Int. Conf. Electr. Mach. Syst. ICEMS 2019, pp. 1-5, 2019, doi: 10.1109/ICEMS.2019.8921473.

[8] E. Al-Hassan, H. Shareef, M. M. Islam, A. Wahyudie, and A. A. Abdrabou, "Improved smart power socket for monitoring and controlling electrical home appliances," IEEE Access, vol. 6, pp. 49292-49305, 2018, doi: 10.1109/ACCESS.2018.2868788.

[9] A. Sulihati, "Aplikasi Akademik Online Berbasis Mobile Android Pada Universitas Tama Jagakarsa," Univ. Tama Jagakarsa, vol. XI, no. 1, pp. 15-26, 2016. 